\title{
Understanding the Role of Creative Self-Efficacy and Power Distance Orientation for Examining the Consequences of Abusive Supervision on Employee Creativity: A Case Study from Nepal
}

\author{
Khusbu Rauniyar1*, Donghong Ding1, Nisha Rauniyar² \\ ${ }^{1}$ School of Management, Department of Business Administration, University of Science and Technology of China, Hefei, China \\ ${ }^{2}$ School of Management, St. Xavier's College, Kathmandu, Nepal \\ Email: *khusburauniyar1@mail.ustc.edu.cn, ddh188@gmail.com, linkinnishi@gmail.com
}

How to cite this paper: Rauniyar, K., Ding, D. H., \& Rauniyar, N. (2017). Understanding the Role of Creative Self-Efficacy and Power Distance Orientation for Examining the Consequences of Abusive Supervision on Employee Creativity: A Case Study from Nepal. Open Journal of Leadership, 6, 61-81.

https://doi.org/10.4236/oj1.2017.62004

Received: May 17, 2017

Accepted: June 26, 2017

Published: June 29, 2017

Copyright () 2017 by authors and Scientific Research Publishing Inc. This work is licensed under the Creative Commons Attribution International License (CC BY 4.0).

http://creativecommons.org/licenses/by/4.0/

\begin{abstract}
The present study investigates the effect of abusive supervision on employee creativity. For this, a psychological cognitive factor such as creative self-efficacy and cultural value namely power distance orientation have been examined based on social cognitive theory. Results are gathered from a survey of 325 full-time employees from 17 companies covering six industries in the central and eastern development regions of Nepal. The results indicate that abusive supervision is negatively related to employee creativity and this relationship is fully mediated by creative self-efficacy. In addition, it is evident from our results that employees' power distance orientation plays a moderating role. The direct effect of abusive supervision on creative self-efficacy and the mediating effect of creative self-efficacy are weaker when the power distance orientation is high rather than low. The implications of our study for both theory and practical are discussed.
\end{abstract}

\section{Keywords}

Abusive Supervision, Employee Creativity, Creative Self-Efficacy, Power Distance

\section{Introduction}

Over the past decade, recent attention has been given to understand the causes and consequences of abusive supervision. Abusive supervision "refers to subordinates' perceptions of the extent to which supervisors engage in the sustained display of hostile verbal and nonverbal behaviors, excluding physical contact" 
(Tepper, 2000). The phenomenon of abusive supervision negatively affects a substantially large number of organizations and their employees (Harvey et al., 2007). Recent research indicates that $10 \%$ to $16 \%$ of employees in USA experience varying degree of abusive supervision (Namie \& Namie, 2000; Hoobler \& Brass, 2006). Due to this, significant increases in absenteeism, health care costs, and productivity declination are noted which lead to an approximate loss of around 23 billion US dollars annually (Tepper et al., 2006). More alarmingly, according to Nepalese media (Himalayan Times and Kantipur News-Nepal's biggest local media organizations), reports indicate that the frequency of such abuse has increased in recent years and nearly $30 \%$ of workers have encountered abusive treatment from their supervisors at the workplace. Several studies have been carried out to understand the role of positive leadership such as transformational leadership (Shin \& Zhou, 2003) and ethical leadership (Ma \& Cheng, 2013) on employee creativity. However, none of the empirical studies have investigated the effect of abusive supervision within Nepalese culture. Given the media reports of increasing abuse in Nepal, it becomes crucial to fill this research gap and determine the impact of abusive supervision on employee creativity and performance in Nepal.

Only a couple of researches have been carried out in the past to study the effect of abusive supervision on employee creativity. Some studies have shown negative relationships (Liu et al., 2012; Zhang et al., 2014) and, one exceptional study found a curvilinear relationship (Lee et al., 2013). This exceptional finding raises questions as what is the potential underlying mechanism through which abusive supervision influences employee creativity. Given the prevalence and far-reaching impact of abusive supervision (Tepper, 2007; Tepper, Carr, Breaux, Geider, Hu, \& Hua, 2009), it is very important to identify the other vital factors that can clarify how and when abusive supervision influences employee creativity (Lee et al., 2013). Knowledge of such factors is crucial for our understanding. This is because, as noted in Tepper (2000), subordinates might frequently be reluctant to report abusive supervisions, but some of them may cope with abusive supervision more effectively than others. Hence, it is both theoretically and empirically important to investigate the influences of abusive supervision on employee creativity (Liu et al., 2012). It is also important to recognize potential mediators and moderators which can clarify how and when employee creativity is influenced by abusive supervision. The present study focuses on this research direction.

Based on the theoretical arguments, it has been emphasized that psychological mechanism is pivotal in explaining the linkages between abusive supervision and employee creativity (Liu et al., 2012). According to Liu et al. (2012) and Grant \& Berry (2011), intrinsic motivation is considered as a strong psychological mechanism which influences employee creativity. Similar to intrinsic motivation, creative self-efficacy motivates the employees to express their creative ideas to pursue their chosen goals (Bandura, 2001). The current study using a social cognitive perspective primarily aims to explore the mediating role of a psychological 
cognitive factor, namely creative self-efficacy, in the relationship between abusive supervision and employee creativity. Literature has further presented that creative self-efficacy represent a pivotal psychological readiness factor that affects a person's behavior, namely, "will" (Choi 2004). Social cognitive theory suggests that leadership style is a critical external factor which does not directly influence individual behavior, yet indirectly influences psychological cognitive factor.

Particularly, power distance orientation, a cultural value (Javidan et al., 2006), refers to the degree which individual believe that organizational or societal power should be distributed unequally (Hofstede, 1980). Individuals with high in power distance orientation are unlikely to view abusive treatment as illegitimate and violating relational bonds (Tyler et al., 2000). They are likely to accept supervisors as their role models, which may lessen the effect of abusive supervision. Thus, power distance orientation is likely to affect the process of creative self-efficacy. In the present study, we examine the moderating role of power distance orientation on the relationship between abusive supervision and creative self-efficacy.

Succinctly, the current study seeks to explore the relationships between abusive supervision and employee creativity. The study provides contribution in the existing literature of abusive supervision and creativity. The theoretical background of our research is included in Section 2 and the proposed hypotheses to be tested are discussed in Section 3. The methodology followed and the results obtained are included in Section 4 and 5, respectively. Section 6 summarizes the discussion and conclusions on our research. Practical implication, limitations of our study as well as future work required in this direction is outlined in Section 7. Based on social cognitive theory, we also investigate potential mediating role of a psychological cognitive factor in the abusive supervision-creativity relationships. Our findings are expected to help educators in obtaining an in-depth understanding of how abusive supervision affects the creativity of employee. Our effort to investigate the moderating role of power distance deepens the understanding of the nature of high power distance orientation employees.

\section{Theoretical Background}

\subsection{Abusive Supervision}

The behavioral approach of supervisors towards their subordinates is crucial for employees and organizations. Abusive supervisory behaviors involves criticizing publicly, making mockery, showing rudeness, breaking promises, inconsiderate actions, and the silent treatments (Bies, 2000). Abusive supervisors often intimidate and humiliate, use derogatory names, shout, and ridicule their employees (Decoster et al., 2013). The abusive supervision has received increasing attention because of its detrimental consequences for employees and organizations (Farh \& Chen, 2014). Although a number of researchers have revealed that abusive supervision has a negative impact and undesirable outcomes (Decoster et al., 2013; Tepper et al., 2009). However, empirical results and the role of abusive su- 
pervision on employee creativity is little and incompatible. Our study attempts to explore internal mechanism of abusive supervision and its consequences on employee creativity.

A large numbers of research has linked abusive supervision to negative consequences for affected employees in the form of decreased work-related attitudes (Tepper, 2000; Duffy et al., 2002), lowered performance (Aryee et al., 2007), diminished psychological well-being (Bowling \& Beehr, 2006; Duffy et al., 2002; Lian et al., 2012; Schat et al., 2006; Tepper et al., 2007). Moreover, employees may respond to abusive supervision with undesirable life outcomes. For example, it has been observed that effects of abusive supervision can often spill over to subordinates' lives away from work (Hoobler \& Brass, 2006; Tepper et al., 2007). Hoobler and Brass (2006) have found that family members of abused employees reported higher levels of undermining at home than family members of employees who did not face abusive supervision. Some scholars have argued that recent modifications in legal procedures and codes may imply that organizations may be held liable for abusive supervisory behaviors occurring in the workplace (Yamada, 2004). Thus, abusive supervision seems to have serious consequences for victimized employees, organizations, and society as a whole.

In hypothesized model as represented in Figure 1, it is proposed that abusive supervision would have negative impact on employee creativity. This impact would be mediated by the creative self-efficacy of the employee. The effect of abusive supervision is assumed to be negatively correlated with creative self-efficacy. Further, the level of power distance orientation of employee is expected to moderate the correlated between abusive supervision and creative self-efficacy.

\subsection{Social Cognitive Theory}

Social cognitive theory has been used by creativity researchers to explore the influencing mechanism of leadership on creativity (Liao et al., 2010). As per this theory, human functioning is a dynamic system comprising reciprocal relationships among three categories of determinants: behavior, cognition, and performance environment (Bandura, 1986). In the theory, the "social" part acknowledges the environmental origins of human thought and action. And the "cognitive" portion identifies the influential contribution of cognitive processes to human action and motivation. The principle thought behind the social cognitive perspective is that thinking, motivation, and behavior of an individual can be self-regulated instead of giving undesirable response to the external situations (McCormick, 2001). Individuals will positively respond to the external environ-

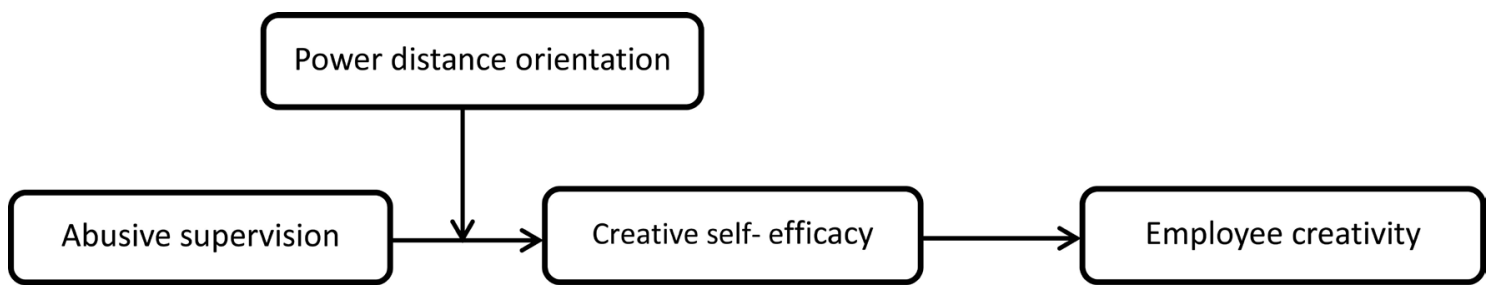

Figure 1. Hypothesized model. 
ment by self-regulating their psychological cognitive factor (e.g. self-efficacy), which eventually affects the employee's behaviors. This finding suggests that through a particular psychological cognitive process, any individuals can initiate the creativity by themselves.

Furthermore, few studies have found that creative self-efficacy, which represents individual's beliefs on their capacity of doing something, is the fundamental cognitive mechanisms driving creativity (Gong et al., 2009). Choi (2004) pointed out that two most important psychological cognitive factors driving the creativity are individual's confidence in creative abilities and willingness to do innovative work. Thus, creative self-efficacy can represent the specific type psychological readiness component needed to unveil the crucial role of psychological cognitive factor in creativity. Leaders have traditionally been considered as important factors for cultivating or strangling employee creativity (George, 2007). Thus, leader's behavior plays significant role in creative thinking of the employees which is necessary for innovation and in releasing employee's creative potential (Zhang et al., 2011).

To clarify the effect of abusive supervision on employee creativity from the perspective of social cognitive theory, the present study examines a specific type of a psychological cognitive factor (i.e., creative self-efficacy) as mediator and a specific cultural value (i.e., power distance) as a moderator.

\section{Proposed Hypotheses}

\subsection{Abusive Supervision and Employee Creativity}

The process of "generation, promotion, and implementation of novel and useful ideas about products, practices, services, or procedures" are referred as employee creativity (Zhou, 2003). This process involves numerous risks, conflicts, difficulties, failures and ethical dilemmas ( $\mathrm{Tu} \& \mathrm{Lu}, 2012$ ), and even failures. It has also been noted that leaders can foster employee creativity (Carmeli et al., 2013). This fostering is achieved if employees are provided good job structure, positive energy, resources, positive psychological conditions, and quality relational exchanges. This intrinsically motivates the employees within an organization. The intrinsic motivation refers to the degree to which an individual perform the activity with enjoy and interest in work itself, rather than under external compulsions and rewards (Deci, 1972). Intrinsic motivation of employee is weakened by abusive supervision as this undermines employee creativity (Liu et al., 2012). Intrinsically motivated employee come up with novel and useful ideas, and adheres to innovative goals and this enhances their creativity (Deci \& Ryan, 2008; Zhou \& George, 2001).

In essence, abusive supervision is considered an important cause of psychological distress (Restubog et al., 2011). This often leads to depression, anxiety, and emotional exhaustion in employees. Consequently, they tend to lose focus and make distance from their jobs (Aryee et al., 2007; Hoobler \& Brass, 2006; Tepper et al., 2004). In such situations, abused employees are left with little scope of developing interest in their work. Therefore, their intrinsic motivation 
decline substantially (Deci \& Ryan, 2008) which gradually reduces their creativity. Such abused employees lose their emotional connection with jobs and begin spending large portion of working hours on private affairs (Chi \& Liang, 2013). Due to lesser time devoted to their jobs, they are unlikely to create useful and innovative ideas, which gradually hamper their creativity.

Earlier researches have concluded that supportive relationships between leaders and subordinates enhance subordinate creativity (Shin \& Zhou, 2003). But abusive supervision can create feelings of being humiliated among the subordinates and this lessens the creativity (Keashly \& Harvey, 2005). Consequently, abused employees are less likely to actively accept challenges and put forward brilliant ideas or solutions. Even sometimes, victims of abusive supervision have strong intentions to quit their job (Tepper et al., 2009).

Therefore, we propose:

H1. Abusive supervision is negatively related to employee creativity.

\subsection{Mediating Role of Creative Self-Efficacy}

Creative self-efficacy is expected to mediate the relationship between abusive supervision and employee creativity. This is an individual's belief that $\mathrm{s} / \mathrm{he}$ has the potential to generate creative ideas (Tierney \& Farmer, 2002). Social cognitive theory emphasizes that individuals with high self-efficacy will persistently put their effort to address uncertainties and potential challenges. This characteristic motivates employees to exert more efforts in the pursuit of the chosen goal even during failures and difficulties. This is pivotal for better achievements, creativity, social integration and health (Liao et al., 2010).

In general, employees self-knowledge depends on how others treat them (McAllister \& Bigley, 2002), specially on workplaces by behaviors of their leaders. Abused employees feel frustration (Greenberg, 1990) and would think that their ideas, thinking, efforts, contributions (Jian et al., 2012) are not useful for the development of organization (Rafferty \& Restubog, 2011). These situations may lead to psychological stress (Restubog et al., 2011) among the employees, which could diminish their belief in their creative capabilities. Furthermore, employees may feel isolated and they would hesitate to discuss their own ideas and thinking with supervisors. Ultimately, abused employees would be unaware of their own creative caliber and become diffident.

As the creative self-efficacy reduces, it weakens the psychological linkage between the employees and their work. This further diminishes their intrinsic motivation to devote their creative skills for the organization (Liu et al., 2012). The reduced linkage of employees with their job can hinder the progress and status of organization. These circumstances attenuate the self-learning and self-development aspirations of employees which may even demolish their self-confidence to produce new ideas and approaches. Consequently, employees would be unable to put forward novel ideas and creative solutions for achieving organization goals, hence exhibiting less creativity. Overall, abusive supervision will lead to declination of creative self-efficacy, and therefore reduces the creativity of employees. 
Therefore, we propose:

H2. Creative self-efficacy mediates the negative relationship between abusive supervision and employee creativity.

\subsection{The Moderating Role of Power Distance Orientation}

Power distance orientation is a cultural value (Javidan et al., 2006) which refers to the extent to which an individual accepts the legitimacy of unevenly allocated power among the workers in organizations (Hofstede, 1980). This has been considered as an important factor which influences the perception and reaction of employees to abusive supervision. In higher power distance orientation, subordinates presumably accept the exerting power from supervisors. Therefore, the abused behavior from supervisor is considered as rightful power display rather than unjust treatment (Kernan et al., 2011). The employees with high power distance orientation believe that leaders should be respected and reverenced, are superior and elite; and therefore accept their leader's decisions (Javidan et al., 2006). Hence, employees those are higher, rather than lower, in power distance orientation have a wider view of acceptable leaders' behaviors and tolerate more forceful actions instead of viewing them as an injustice (Kim \& Leung, 2007; Leung \& Lind, 1986; Morris \& Leung, 2000).

Employees with low power distance orientation view their supervisors as approachable (Hofstede, 1980) and are likely to have personal connections with them (Tyler et al., 2000). Such employees attempt to make "a stronger social bond with the authority" (Tyler et al., 2000). High power distance orientation employees, however, are unlikely to expect or develop such social relations between subordinates and supervisors believing that it is not how the two levels should interact (Bochner \& Hesketh, 1994). Such employees expect and develop relationships that are formal, rigid, and impersonal with their supervisors (Tyler et al., 2000). In low power distance orientation, subordinates are more surprised by abusive supervisory treatment, and therefore are more influenced by it. However, employees with high power distance orientation hardly react adversely to abusive and unjust treatments from supervisors (Lee et al., 2000). Summarizing these ideas, abusive supervision effects are likely to be weakened by high power distance orientation as was hypothesized by Tepper (2007), and is examined in the current study.

Overall, the detrimental effect of abusive supervision is dampened due to high power distance orientation. As employee creative self-efficacy is negatively correlated with abusive supervision, the negative effect of such abuses will be relatively weaker with high power distance orientation. In contrast, the effect of abusive supervision on creative self-efficacy is relatively stronger with low power distance orientation. Therefore, it is reasonable to assume that power distance would act as moderator between the negative effect of abusive supervision and creative self-efficacy.

Thus, we predict:

H3. The relationship between abusive supervision and creative self-efficacy is 
moderated by power distance orientation, such that the relationship is weaker with high power distance orientation and stronger with low power distance orientation.

\subsection{Power Distance Orientation as Moderator for the Mediating Effect of Creative Self-Efficacy}

We note two important associations: (a) the role of moderation by power distance orientation while relating abusive supervision and creative self-efficacy (b) as per the logic of moderated mediation model by Edwards and Lambert (2007), the positive correlation between creative self-efficacy and employee creativity. Based on this, power distance orientation is expected to moderate the mediating effect of creative self-efficacy. As aforementioned, individuals with low power distance orientation are more likely to react to abusive supervision at cost of reducing their creative self-efficacy. The negative effect of abusive supervision on creativity of such employees is increased through strong mediating effect of creative self-efficacy. In particular, employees who have high power distance orientation are relatively less influenced by abusive supervisors via enhancing their creative capabilities to some extent. Thus abusive supervision does not strongly influence the creativity of such employees. Conversely, employees with low power-distance orientation are strongly influenced by abusive supervision via significantly reducing their creative self-efficacy which results in substantial decline in creative capabilities. Conclusively, if there is low power distance orientation then abusive supervision has a stronger negative influence on employee creativity; else its influence would be relatively weaker.

Based on the above, we predict:

H4. Power distance orientation moderates the mediating effect of creative self-efficacy on the abusive supervision-creativity relationship, such that the mediating effect is stronger when the level of power distance orientation is low rather than high.

\section{Methodology and Sample}

Our sample includes 325 full-time employees working in 17 different companies located across the central and Eastern development regions of Nepal. Wu et al. (2010) noted that diversification in sample improves the generalizability of research findings. Thus, we distributed the questionnaires among people working in diverse industries. To guarantee that our sample is diverse in nature, people were contacted and invited through convenience sampling procedure. People were mainly from private enterprises (e.g., sales, manufacturing, technology, service and construction) and public sectors. We distributed paper-based questionnaires to employees on site and were collected back on the spot. During the pilot phase, we asked the participants to provide their comments on the questionnaire to ensure its quality. We also informed the participants about the objective of this survey and the procedures to fill in the questionnaire. We requested the participants to evaluate abusive behavior they perceived from their 
supervisors, their creative self-efficacy, power distance, and creativity. We assured the employees that the information provided by them would be kept confidential. Our questionnaire was based on the principles which can assure that it would be correctly responded by the respondents. For example, we maintained the flow of questionnaire, kept it short and simple, questions were neutral in nature, avoided double barreled and double negative questions, same scale was chosen for every measures. Among the 345 surveys distributed, 325 were returned complete (with a $94.2 \%$ response rate). Therefore, we discarded 20 questionnaires due to missing data. The detailed demographic information of the sample is shown in Table 1.

\section{Measures}

The items in the survey were adapted from existing literature to guarantee its validity. The questions were formulated to be answered based on a 5-point Likert scale (ranging from 1 = "strongly disagree" to 5 = "strongly agree"). All measures were originally formulated in English. Given that some of the respondents were all native Nepalese speakers, all the English measures were translated into Nepalese. Further, to ensure the validity and appropriateness of the survey questions in the Nepalese context, back-translation procedures were adopted (Brislin, 1970).

\section{Abusive Supervision}

We used Tepper's (2000) fifteen-item scale to measure perceptions of abusive supervision (Cronbach's $\alpha=0.93$ ). Sample items included, "My supervisor ridi-

Table 1. Demographic profile of participants.

\begin{tabular}{|c|c|c|c|}
\hline Items & Category & Frequency & $\%$ \\
\hline \multirow{2}{*}{ Gender } & Male & 198 & 60.9 \\
\hline & Female & 127 & 39.1 \\
\hline \multirow{5}{*}{ Age } & 25 years or less & 45 & 13.8 \\
\hline & $26-30$ & 112 & 34.5 \\
\hline & $31-35$ & 75 & 23.1 \\
\hline & $36-40$ & 40 & 12.3 \\
\hline & Above 41 & 53 & 16.3 \\
\hline \multirow{5}{*}{ Tenure } & Less than 1 year & 99 & 30.5 \\
\hline & $2-4$ years & 75 & 23.1 \\
\hline & $5-7$ years & 19 & 5.8 \\
\hline & $8-10$ years & 19 & 5.8 \\
\hline & More than 10 years & 113 & 34.8 \\
\hline \multirow[t]{5}{*}{ Education Level } & Below High School & 10 & 3.1 \\
\hline & High School & 81 & 30.0 \\
\hline & Associate's degree (e.g. a two year education diploma) & 129 & 39.7 \\
\hline & Bachelor's degree & 101 & 31 \\
\hline & Master degree or above & 4 & 1.2 \\
\hline Note: $\mathrm{n}=325$ & & & \\
\hline
\end{tabular}


cules me" and "My supervisor tells me my thoughts and feelings are stupid" are representative items. $(1=$ never, $5=$ very frequently $)$.

\section{Creative Self-Efficacy}

Creative self-efficacy was measured with Tierney and Farmer's (2002) three-item scale $(\alpha=0.80)$. Representative items included, "I have confidence in my ability to solve problems creatively" and "I feel that I am good at generating novel ideas" ( 1 = strongly disagree, 5 = strongly agree).

\section{Employee Creativity}

Six-item scale of Zhou and George (2001) are used to measure employee creativity ( $\alpha=0.93$ ). Sample items included, "I often suggest new ways of performing work tasks" and "I often come up with creative solutions to problem" and (1 = strongly disagree, 5 = strongly agree).

\section{Power Distance}

Six-item scale of Dorfman and Howell (1988) are adapted to measure power distance $(\alpha=0.79)$. Sample items included, "Managers should not delegate important task to employees" and "It is frequently necessary for a manager to use authority and power when dealing with subordinates" ( $1=$ strongly disagree, $5=$ strongly agree).

\section{Control Variables}

As the four demographic variables (gender, age, education, and tenure) have a significant role in employee creativity, they were controlled in the current study (Zhou \& George, 2003; Shalley \& Gilson, 2004). Age was measured in years. Gender was dummy coded $(1=$ male and $0=$ female). Job tenure of the employees were also controlled ( $1=$ Less than 1 year, $2=2-4$ years, $3=5-7$ years, $4=8-10$ years, $5=$ more than 10 years).

\section{Results}

\subsection{Hypothesis Testing}

In the current study, hierarchical multiple regression analysis was applied to test hypothesis $\mathrm{H} 1 \mathrm{H} 2, \mathrm{H} 3$ and $\mathrm{H} 4$. For $\mathrm{H} 1$ and $\mathrm{H} 2$, first, the independent variable is found to be significantly related to the dependent variable and the mediator, respectively. Second, the mediator is also significantly related to the dependent variable. Finally, on incorporating the mediator into the regression equation, coefficient of the independent variable is noted to be smaller. For H3, the control variables were entered in Step 1. The independent variable and moderator in entered in Step 2 and 3, respectively. Finally, the interaction term is entered. We also carried our bias-corrected bootstrapping procedure to test hypothesis $\mathrm{H} 2$ and H4 developed by Preacher and Hayes (2008).

\subsection{Validity and Reliability}

For making an assessment of the reliability and validity of the multi-item mea- 
surement scale, we carried out confirmatory factor analysis (CFA). Table 2 shows that Cronbach's $\alpha$ ranged from 0.79 to 0.83 , which are higher than the benchmark value of 0.70 . This indicates all the variables have acceptable reliability. For testing the convergent validity, the composite reliability of constructs and average variance extracted (AVE) were assessed. The values of composite reliability ranged between 0.86 and 0.94 , which are higher than the benchmark value of 0.70 . The AVE scores ranged from 0.55 to 0.71 and are higher than the benchmark value of 0.50 . These results indicate that the convergent validity of our measurement is good. For making an assessment of discriminant validity of the items, we compared the relationship between the correlations among the constructs and square roots of AVE scores. Table 3 shows that the square roots of the AVEs for all construct were greater than the correlations between constructs. Thus, the discriminant validity of the measurements is confirmed.

\subsection{Descriptive Statistics and Inter Correlations}

The mean, standard deviation and correlation for all variables are summarized in Table 3. The result supports all of our hypotheses. As indicated in Table 3, abusive supervision is negatively related to employee creativity (correlation coefficient $\mathrm{r}=-0.18, \mathrm{p}<0.01)$ and creative self-efficacy $(\mathrm{r}=-0.12, \mathrm{p}<0.05)$. Moreover, creative self-efficacy is positively related to employee creativity $(r=0.51, p$ $<0.01)$. The variance inflation factors during hierarchical regression analyses ranged between 1.01 and 1.09 , which means that multicollinearity problems are

Table 2. Loading, cronbach's $\alpha$, composite reliability and average variance extracted (AVE).

\begin{tabular}{ccccc}
\hline Variables & Loading & Cronbach's $\alpha$ & Composite reliability & AVE \\
\hline Abusive supervision & $0.73-0.82$ & 0.83 & 0.88 & 0.59 \\
Employee creativity & $0.62-0.84$ & 0.93 & 0.94 & 0.55 \\
Creative self-efficacy & $0.81-0.86$ & 0.80 & 0.88 & 0.71 \\
Power distance & $0.67-0.84$ & 0.79 & 0.86 & 0.55 \\
\hline
\end{tabular}

Table 3. Mean standard deviations, correlation and square roots of AVE in diagonals.

\begin{tabular}{|c|c|c|c|c|c|c|c|c|c|c|}
\hline Variables & & $\mathrm{SD}$ & 1 & 2 & 3 & 4 & 5 & 6 & 7 & 8 \\
\hline Gender & 0.60 & 4.86 & & & & & & & & \\
\hline Age & 2.82 & 1.28 & 0.08 & & & & & & & \\
\hline Education & 3.01 & 0.86 & -0.04 & $-0.20^{\star *}$ & & & & & & \\
\hline Profession & 2.90 & 1.70 & $-0.33^{\star *}$ & $-0.16^{\star *}$ & $0.26^{\star *}$ & & & & & \\
\hline Abusive supervision & 1.35 & 0.50 & $0.15^{\star \star}$ & 0.01 & -0.07 & -0.10 & $(0.74)$ & & & \\
\hline Employee creativity & 3.83 & 0.57 & $0.13^{*}$ & -0.03 & -0.01 & -0.05 & $-0.18^{\star *}$ & $(0.76)$ & & \\
\hline Creative self-efficacy & 3.75 & 0.53 & $0.20^{\star *}$ & -0.04 & 0.06 & -0.00 & $-0.12^{\star}$ & $0.51^{\star *}$ & $(0.84)$ & \\
\hline Power distance & 2.37 & 0.68 & 0.01 & $0.16^{* *}$ & -0.02 & 0.60 & $0.12^{*}$ & 0.08 & -0.10 & $(0.74)$ \\
\hline
\end{tabular}

Notes: $\mathrm{n}=325$. Values in parentheses on the diagonals are the square roots of AVE of each scale. ${ }^{*} \mathrm{p}<0.05$; ${ }^{* *} \mathrm{p}<0.01$. 
Table 4. Results of mediating effect of creative self-efficacy.

\begin{tabular}{ccccccc}
\hline & \multicolumn{3}{c}{ Creative-self efficacy } & \multicolumn{3}{c}{ Employee creativity } \\
\cline { 2 - 7 } & Model 1 & Model 2 & Model 3 & Model 4 & Model 5 & Model 6 \\
\hline Gender & $0.23^{* * *}$ & $0.25^{* * *}$ & $0.14^{*}$ & $0.17^{*}$ & 0.02 & 0.05 \\
Age & -0.05 & -0.05 & -0.05 & -0.05 & -0.03 & -0.03 \\
Education & 0.04 & 0.03 & -0.02 & -0.03 & -0.04 & -0.05 \\
Tenure & 0.05 & $0.05-$ & -0.01 & -0.02 & -0.04 & -0.04 \\
Abusive supervision & & $-0.16^{*}$ & & $-0.22^{* * *}$ & & $-0.14^{* *}$ \\
Creative self-efficacy & & & & & $0.51^{* * *}$ & $0.49^{* * *}$ \\
$\mathrm{R}^{2}$ & 0.52 & 0.76 & 0.22 & 0.67 & 0.27 & 0.28 \\
$\Delta \mathrm{R}^{2}$ & 0.52 & 0.24 & 0.22 & 0.45 & 0.25 & 0.22 \\
$\mathrm{~F}$ & $4.41^{*}$ & $5.27^{* * *}$ & 1.78 & $4.58^{* * *}$ & $23.6^{* * *}$ & $21.5^{* * *}$ \\
$\Delta \mathrm{F}$ & $4.41^{*}$ & $8.31^{*}$ & 1.78 & $15.4^{* * *}$ & $108.6^{* * *}$ & $98.9^{* * *}$ \\
\hline
\end{tabular}

Notes: $\mathrm{n}=325^{*} \mathrm{p}<0.05 ;{ }^{* *} \mathrm{p}<0.01 ;{ }^{* *} \mathrm{p}<0.001$.

minimal in the present research.

Table 4 shows that abusive supervision is significantly related to creative self-efficacy $(\beta=-0.16, \mathrm{p}<0.05$, Model 2$)$ and employees creativity $(\beta=-0.22$, $\mathrm{p}<0.001$, Model 4$)$. In addition, creative self-efficacy is significantly associated with employees' creativity $(\beta=0.51, \mathrm{p}<0.001$, Model 5$)$. Third, when creative self-efficacy is included in the regression equation, the effect of abusive supervision on employees' creativity $(\beta=-0.14, \mathrm{p}<0.01$, Model 6$)$ is not significant. However, creative self-efficacy is still significantly related to employee creativity ( $\beta$ $=0.49, \mathrm{p}<0.001$, Model 6 ). This suggests that the relationship between abusive supervision and employee creativity is fully mediated by creative self-efficacy. Hence, the hypotheses $\mathrm{H} 1$ and $\mathrm{H} 2$ are supported.

The results show that employees' power distance negatively moderates the direct relationship between abusive supervision and creative-self efficacy. This is found to be consistent with our hypotheses. Table 5 shows that the interaction between abusive supervision and power distance is positively related to creative self-efficacy (coefficient of correlation $\beta=0.13$, Model 4). Figure 2 shows that abusive supervision is more negatively related to creative self -efficacy when power distance is low rather than high. Accordingly, the hypothesis stated in H3 is supported.

$\mathrm{H} 4$ assumes that power distance moderates the abusive supervision $\rightarrow$ creative self-efficacy $\rightarrow$ employee creativity mediating linkage. Bootstrapping test of Edwards and Lambert (2007) is carried out to test the hypothesis H4.

The result obtained from moderating effect of power distance is tabulated in Table 6. Also, Table 7 clearly shows that abusive supervision is negatively related to creative self-efficacy $(\beta=-0.24, \mathrm{p}<0.05)$ for employees with low power distance orientation. Whereas this negative relationship is not significant $(\beta=$ $-0.06, \mathrm{~ns})$ for the employees with high power distance orientation. The difference between the above two coefficients is significant $(\Delta \beta=0.14, \mathrm{p}<0.05)$. 
Table 5. Indirect effects of abusive supervision (via creative self-efficacy) on employee creativity.

\begin{tabular}{cccc}
\hline Path & $\begin{array}{c}\text { Abusive } \\
\text { supervision } \rightarrow\end{array}$ & $\begin{array}{c}\text { Creative } \\
\text { self-efficacy } \rightarrow\end{array}$ & $\begin{array}{c}\text { Employee } \\
\text { creativity }\end{array}$ \\
\hline Bootstrap-indirect effect & -0.07 & \\
Standard error & 0.03 & \\
Lower limit 95\% CI & -0.15 & \\
Upper limit 95\% CI & -0.01 & \\
\hline
\end{tabular}

Notes: $\mathrm{n}=325$. Adjusted $\mathrm{R}^{2}=0.28, \mathrm{~F}(6318)=21.48, \mathrm{p}<0.001$. Confidence intervals are bias-corrected based on 10,000 bootstrap samples. Control variables: gender, age, education level and tenure. ${ }^{*} \mathrm{p}<0.05$; ${ }^{* *} \mathrm{p}$ $<0.01 ;{ }^{* * *} \mathrm{p}<0.001$.

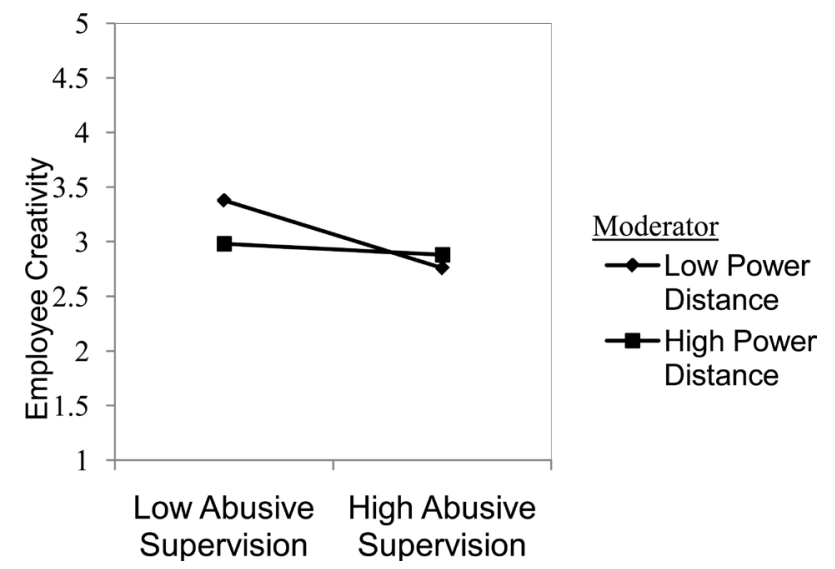

Note: High power distance is indicated by a square; low power distance is indicated by a diamond.

Figure 2. Plot of intersection between abusive supervision and power distance on creative self-efficacy.

Table 6. Results of moderating effect of power distance.

\begin{tabular}{ccccc}
\hline & \multicolumn{5}{c}{ Creative-self efficacy } \\
\hline Model 1 & Model 2 & Model 3 & Model 4 \\
\hline Age & $0.23^{* * *}$ & $0.25^{* * *}$ & $0.25^{* * *}$ & $0.25^{* * *}$ \\
Education & -0.05 & -0.05 & -0.03 & -0.04 \\
Tenure & 0.04 & 0.03 & 0.03 & 0.05 \\
Abusive supervision & 0.06 & 0.05 & 0.06 & 0.06 \\
Power distance & & $-0.16^{* *}$ & $-0.15^{* *}$ & $-0.18^{* *}$ \\
Abusive supervision $\times$ Power distance & & & -0.08 & -0.07 \\
$\mathrm{R}^{2}$ & & & & $0.13^{*}$ \\
$\Delta \mathrm{R}^{2}$ & 0.05 & 0.07 & 0.08 & 0.09 \\
$\mathrm{~F}$ & 0.05 & 0.02 & 0.006 & 0.01 \\
$\Delta \mathrm{F}$ & $4.41^{* *}$ & $5.27^{* * *}$ & $4.77^{* * *}$ & $4.86^{* * *}$ \\
& $4.41^{* *}$ & $8.31^{* *}$ & 2.17 & $5.05^{*}$ \\
\hline
\end{tabular}

Notes: $\mathrm{n}=325,{ }^{*} \mathrm{p}<0.05 ;{ }^{* *} \mathrm{p}<0.01 ;{ }^{* * *} \mathrm{p}<0.001$. 
Table 7. Results of the moderated path analysis.

\begin{tabular}{ccccccc}
\hline & \multicolumn{5}{c}{$\begin{array}{c}\text { Abusive supervision }(X) \rightarrow \text { Creative self-efficacy }(M) \rightarrow \\
\text { Employee creativity }(Y)\end{array}$} \\
\cline { 2 - 7 } Moderator variable & \multicolumn{4}{c}{ Stage } & \multicolumn{3}{c}{ Effect } \\
\cline { 2 - 6 } & First & Second & $\begin{array}{c}\text { Direct } \\
\text { effects }\end{array}$ & $\begin{array}{c}\text { Indirect } \\
\text { effects }\end{array}$ & Total effects \\
\cline { 2 - 6 } & $P_{M X}$ & $P_{Y M}$ & $P_{Y X}$ & $\left(P_{Y M} P_{M X}\right)$ & $\left(P_{Y X}+P_{Y M} P_{M X X}\right)$ \\
\hline Simple paths for low power distance & $-0.24^{*}$ & $0.54^{*}$ & $-0.12^{*}$ & $-0.11^{*}$ & $-0.24^{*}$ \\
Simple paths for high power distance & -0.06 & $0.43^{*}$ & $-0.11^{*}$ & -0.02 & $-0.14^{*}$ \\
Differences & $0.18^{*}$ & -0.11 & 0.01 & $0.09^{*}$ & 0.10 \\
\hline
\end{tabular}

Notes: $\mathrm{n}=325$. $P_{M X}$, path from abusive supervision to creative self-efficacy; $P_{Y M}$, path from creative self-efficacy to employee creativity; $P_{Y X}$ path from abusive supervision to employee creativity. Low power distance refers to the mean of power distance minus one standard deviation; high power distance refers to the mean of power distance plus one standard deviation. ${ }^{*} \mathrm{p}<0.05$.

Therefore, the negative relationship between abusive supervision and creative self-efficacy is strengthened at a low power distance orientation. This provides an additional confirmation for hypothesis $\mathrm{H} 3$. In addition to this, Table 7 shows that the indirect effect of abusive supervision on employee creativity via creative self-efficacy is significant $(\beta=-0.11, \mathrm{p}<0.05)$ at a low power distance orientation. Whereas for high power distance orientation employees, the indirect relationship is insignificant $(\beta=-0.02, \mathrm{~ns})$. Moreover, the difference between the above two coefficients is significant $(\Delta \beta=0.09, \mathrm{p}<0.05)$. Hence, hypothesis $\mathrm{H} 4$ is supported.

The indirect effect of abusive supervision on employee creativity via creative self-efficacy is negative and significant (indirect effect $=-0.07$, lower limit 95 percent $\mathrm{CI}=-0.15$ to -0.01 ), which is excluded 0 ; as shown in Table 5. Thus, the hypothesis $\mathrm{H} 2$ is supported. The model is significant, adjusted $\mathrm{R}^{2}=0.28, \mathrm{~F}$ $(6,318)=21.48, \mathrm{p}<0.001$.

\section{Discussion and Conclusions}

\subsection{Discussion}

The current study examined the effect of abusive supervision on employee creativity. The effect is mediated by a psychological cognitive factor namely creative self-efficacy and moderated by power distance orientation. Our study found negative relationship between abusive supervision and employee creativity. The results are similar to studies reported on Chinese organizations (Zhang et al., 2014). However, the correlation coefficient between abusive supervision and employee creativity was found to be $35 \%$ smaller than that noted for organizations in western countries (Liu et al., 2012). Our study is not in agreement with an exceptional study of Lee et al. (2013). This is probably because the sample of Lee et al. (2013) is from the public organizations of Korea which may prevent to generalize their study. We think that our findings offered evidence for generalizability as we collected samples from different organizations ranging from public 
to private sectors. Our findings also help to understand the negative aspects of leadership and its adverse effect on employee creativity.

Use of multiwave, multisource research design supports all the four hypotheses, H1, H2, H3 and $\mathrm{H} 4$ as stated above. It has been speculated by Tepper (2007) that negative effects of abusive supervision should be weakened to high power distance orientation individuals. In our study, we have confirmed their speculation. Liu et al. (2012) suggested working further on potential psychological mechanisms linking between abusive supervision and creativity. Our study in particular identifies the research gap and attempts to fill that. Based on the social cognitive theory, we predicted that abusive supervision has the negative impact on employee creativity.

Our analyses suggest a mediating role of creative self-efficacy in the relationship between abusive supervision and employee creativity. Our result is in agreement with Gong et al. (2009) where it was noted that intrinsic motivation just operates as self-efficacy. We also found that high power distance orientation would weaken the relation between abusive supervision and employee creativity. Earlier studies have also found intrinsic motivation as a strong mediating mechanism (Ma \& Cheng, 2013; Zhang et al., 2014). Thus, the present study provides additional proofs, using social cognitive perspective, for the motivational process helpful for employees, thereby explains the domain of abusive supervision.

It is confirmed that power distance orientation moderates the effect of abusive supervision and creative self-efficacy. Tepper et al. (2009) found that abusive supervision is moderated by intention to quit while management style is identified as the important moderator in the study of Thau et al. (2009). In our investigation, the power distance orientation is explored. The study offers new evidence, as well as a new approach to explain the moderating effect in the relationship between abusive supervision and employee creativity.

It is also pointed out that we have $61 \%$ male and $39 \%$ female participants in our survey. There might be a difference in the way. Males view themselves as victims. Further, the ways subordinates respond to abusive supervision vary with genders. Therefore, some difference in our results is expected with varying the proportion of gender in our sample. Future research must take this point into account. In most of the earlier studies, subordinates from different organizations having different supervisors are included. However, the perception of supervisors towards their subordinates must be included to prevent any bias in such studies. Therefore, it would be interesting to examine how a group of subordinates perceive the varying degree of abusive supervision of a particular supervisor. We are of opinion that collection of data from supervisors' viewpoint for their subordinates would be difficult and may involve inherent bias. Thus, our study contributes in literature of leadership and creativity, especially to the field of abusive supervision and employee creativity and emphasizes the limitations of such studies undertaken based only on the subordinates viewpoints. 


\subsection{Conclusions}

Our study shows negative consequences of abusive supervision on employee creativity. It also shows that employee creativity can be enhanced by intensifying the confidence of employees in their capability to succeed in spite of difficulties. Our results from power distance factor show that organization should encourage their employees neither to view abused leaders as their role models nor to build strong social bond with their supervisors instead they should react to the abusive supervisory treatment. Our study emphasizes that the role of Nepalese cultural values in the management practice should be implemented. This is consistent with reported studies on the cross-cultural management where it is noted that cultural values are decisive to know how employees react to different leadership behaviors (Kirkman et al., 2006). We hope this study emphasizes the role of culturally meaningful mechanism, employee creativity and creative self-efficacy for the dynamics of abusive supervision.

\section{Practical Implications, Limitation and Future Research}

Our findings have significant practical implications for the organization. As we found that abusive supervision hampers employee creativity, this result warns that organizations should avoid abusive supervision. Organization should make all the efforts to reduce the occurrence of abusive supervision. The authorities should adopt a zero-tolerance policy with regards to abusive supervision (Sutton, 2007) and should monitor the performance of supervisors to ensure that they engage in appropriate, healthy management behaviors when working with their employees. The managers should encouraged themselves to take feedback from their employees to perceive their managerial style. Additionally, managers should participate in leadership development programs, and they should be trained in the area of emotional intelligence, interpersonal relationship skills and anger management (Xu et al., 2012). Employees should also be ready to complain to the higher authorities about the abused behavior so that higher authorities can take action for the betterment of the organization and employees.

This study inevitably has some limitations. Our analysis was not based on random population sampling, which might reduce the generalizability of our findings to some extent. Even so, convenience sampling might not be the problem unless one is looking to generalize one's result to specific population (Highhouse \& Gillespie, 2009). While not doing so, the main concern is whether or not the samples are appropriate for the study conducted. Therefore, future research in this direction could use random population to complement this study.

All the variables of our study were self-reported, especially employee creativity. Although, self-reported creative performance has been accepted in the literature (e.g. Shalley et al., 2009), the possibility of inherent biasness in self-reported varibales cannot be avoided completely. Therefore, future research should aim to use external evaluation such as from their supervisors or workmate. 
It is worthwhile to study the mechanism that investigates creative self-efficacy linking the relationship between abusive supervision and employee creativity. Further work is required to explore other additional mediating mechanisms from different theoretical perspectives, in the relationship between abusive supervision and employee creativity. As the respondents of this study were Nepalese people, it is also conceivable that the effects observed here may vary across cultures. Therefore other cultural differences should be included in further research. This is because the effect of abusive supervision on employee creativity may vary with differing cultural backgrounds. Future research may examine the effect of abusive supervision on employee's performance, and satisfaction taking an in-depth consideration.

\section{Acknowledgements}

This work is supported by the Chinese Academy of Sciences (CAS) and The World Academy of Sciences (TWAS) fellowship scheme.

\section{References}

Aryee, S., Chen, Z. X., Sun, L., \& Debrah, Y. A. (2007). Antecedents and Outcomes of Abusive Supervision: Test of a Trickle-Down Model. Journal of Applied Psychology, 92, 191-201. https://doi.org/10.1037/0021-9010.92.1.191

Bandura, A. (1986). Social Foundations of Thought and Action: A Social Cognitive Theory. Englewood Cliffs, NJ: Prentice-Hall, Inc.

Bandura, A. (2001). Social Cognitive Theory: An Agentic Perspective. Annual Review of Psychology, 52, 1-26. https://doi.org/10.1146/annurev.psych.52.1.1

Bies, R. J. (2000). Interactional (In)Justice: The Scared and the Profane. In J. Greenberg, \& R. Cropanzano (Eds.), Advances in Organizational Justice (pp. 89-118). Stanford, CA: Stanford University Press.

Bochner, S., \& Hesketh, B. (1994). Power Distance, Individualism/Collectivism, and JobRelated Attitudes in a Culturally Diverse Work Group. Journal of Cross-Cultural Psychology, 25, 233-257. https://doi.org/10.1177/0022022194252005

Bowling, N. A., \& Beehr, T. A. (2006). Workplace Harassment from the Victim's Perspective: A Theoretical Model and Meta-Analysis. Journal of Applied Psychology, 91, 9981012. https://doi.org/10.1037/0021-9010.91.5.998

Brislin, R. W. (1970). Back-Translation for Cross-Cultural Research. Journal of CrossCultural Psychology, 1, 185-216. https://doi.org/10.1177/135910457000100301

Carmeli, A., Gelbard, R., \& Reiter-Palmon, R. (2013). Leadership, Creative ProblemSolving Capacity, and Creative Performance: The Importance of Knowledge Sharing. Human Resource Management, 52, 95-121. https://doi.org/10.1002/hrm.21514

Chi, S. C. S., \& Liang, S. G. (2013). When Do Subordinates' Emotion-Regulation Strategies Matter? Abusive Supervision, Subordinates' Emotional Exhaustion, and Work Withdrawal. The Leadership Quarterly, 24, 125-137.

Choi, J. N. (2004). Individual and Contextual Predictors of Creative Performance: The Mediating Role of Psychological Processes. Creativity Research Journal, 16, 187-199. https://doi.org/10.1080/10400419.2004.9651452

Deci, E. (1972). Intrinsic Motivation, Extrinsic Reinforcement, and Inequity. Journal of Personality and Social Psychology, 22, 113-120. https://doi.org/10.1037/h0032355

Deci, E. L., \& Ryan, R. M. (2008). Facilitating Optimal Motivation and Psychological 
Well-Being across Life's Domains. Canadian Psychology, 49, 14-23. https://doi.org/10.1037/0708-5591.49.1.14

Decoster, S., Camps, J., Stouten, J., Vandevyvere, L., \& Tripp, T. M. (2013). Standing by Your Organization: The Impact of Organizational Identification and Abusive Supervision on Followers' Perceived Cohesion and Tendency to Gossip. Journal of Business Ethics, 118, 623-634. https://doi.org/10.1007/s10551-012-1612-z

Dorfman, P. W., \& Howell, J. P. (1988). Dimensions of National Culture and Effective Leadership Patterns: Hofstede Revisited. Advances in International Comparative Management, 3, 127-150.

Duffy, M. K., Ganster, D., \& Pagon, M. (2002). Social Undermining in the Workplace. Academy of Management Journal, 45, 331-351. https://doi.org/10.2307/3069350

Edwards, J. R., \& Lambert, L. S. (2007). Methods for Integrating Moderation and Mediation: A General Analytical Framework Using Moderated Path Analysis. Psychological Methods, 12, 1-22. https://doi.org/10.1037/1082-989X.12.1.1

Farh, C. I. C., \& Chen, Z. (2014). Beyond the Individual Victim: Multilevel Consequences of Abusive Supervision in Teams. Journal of Applied Psychology, 99, 1074-1095. https://doi.org/10.1037/a0037636

George, M. J. (2007). Creativity in Organizations. Academy of Management Annals, 1, 439-477. https://doi.org/10.1080/078559814

Gong, Y., Huang, J.-C., \& Farh, J.-L. (2009). Employee Learning Orientation, Transformational Leadership, and Employee Creativity: The Mediating Role of Employee Creative Self-Efficacy. Academy of Management Journal, 52, 765-778. https://doi.org/10.5465/AMJ.2009.43670890

Grant, A. M., \& Berry, J. (2011). The Necessity of Others Is the Mother of Invention: Intrinsic and Prosocial Motivations, Perspective-Taking, and Creativity. Academy of Management Journal, 54, 73-96. https://doi.org/10.5465/AMJ.2011.59215085

Greenberg, J. (1990). Organizational Justice: Yesterday, Today, and Tomorrow. Journal of Management, 16, 399-432. https://doi.org/10.1177/014920639001600208

Harvey P., Stoner, J., Hochwarter, W., \& Kacmar, C. (2007). Coping with Abusive Supervision: The Neutralizing Effects of Ingratiation and Positive Affect on Negative Employee Outcomes. The Leadership Quarterly, 18, 264-280.

Highhouse, S., \& Gillespie, J. Z. (2009). Do Samples Really Matter That Much? In C. E. Lance, \& R. J. Vandenberg (Eds.), Statistical and Methodological Myths and Urban Legends: Doctrine, Verity and Fable in the Organizational and Social Sciences (pp. 247-265). New York: Routledge.

Hofstede, G. H. (1980). Culture's Consequences: International Differences in Work-Related Values. Beverly Hills, CA: Sage.

Hoobler, J. M., \& Brass, D. J. (2006). Abusive Supervision and Family Undermining as Displaced Aggression. Journal of Applied Psychology, 91, 1125-1133. https://doi.org/10.1037/0021-9010.91.5.1125

Javidan, M., Dorfman, P. W., de Luque, M. S., \& House, R. J. (2006). In the Eye of the Beholder: Cross Cultural Lessons in Leadership from Project GLOBE. Academy of Management Perspectives, 20, 67-90. https://doi.org/10.5465/AMP.2006.19873410

Jian, Z., Kwan, H. K., Qiu, Q., Liu, Z. Q., \& Yim, F. H.-K. (2012). Abusive Supervision and Frontline Employees' Service Performance. The Service Industries Journal, 32, 683698. https://doi.org/10.1080/02642069.2011.614338

Keashly, L., \& Harvey, S. (2005). Emotional Abuse in the Workplace. In S. Fox, \& P. E. Spector (Eds.), Counterproductive Work Behavior: Investigations of Actors and Targets (pp. 201-235). Washington DC: American Psychological Association. 
https://doi.org/10.1037/10893-009

Kernan, M. C., Watson, S., Chen, F. F., \& Kim, T. G. (2011). How Cultural Values Affect the Impact of abusive Supervision on Worker Attitude. Cross Cultural Management, 18, 464-484. https://doi.org/10.1108/13527601111179528

Kim, T., \& Leung, K. (2007). Forming and Reacting to Overall Fairness: A Cross-Cultural Comparison. Organizational Behavior and Human Decision Processes, 104, 83-95.

Kirkman, B. L., Lowe, K. B., \& Gibson, C. B. (2006). A Quarter Century of Culture's Consequences: A Review of Empirical Research Incorporating Hofstede's Cultural Values Framework. Journal of International Business Studies, 37, 285-232.

Lee, C., Pillutla, M., \& Law, K. S. (2000). Power-Distance, Gender and Organizational Justice. Journal of Management, 26, 685-704. https://doi.org/10.1177/014920630002600405

Lee, S., Yun, S., \& Srivastava, A. (2013). Evidence for a Curvilinear Relationship between Abusive Supervision and Creativity in South Korea. The Leadership Quarterly, 24, 724731.

Leung, K., \& Lind, E. A. (1986). Procedural Justice and Culture: Effects of Culture, Gender, and Investigator Status on Procedural Preferences. Journal of Personality and Social Psychology, 50, 1134-1140. https://doi.org/10.1037/0022-3514.50.6.1134

Lian, H., Ferris, D. L., \& Brown, D. J. (2012). Does Power Distance Exacerbate or Mitigate the Effects of Abusive Supervision? It Depends on the Outcome. Journal of Applied Psychology, 97, 107-123. https://doi.org/10.1037/a0024610

Liao, H., Liu, D., \& Loi, R. (2010). Looking at Both Sides of the Social Exchange Coin: A Social Cognitive Perspective on the Joint Effects of Relationship Quality and Differentiation on Creativity. Academy of Management Journal, 53, 1090-1099.

https://doi.org/10.5465/AMJ.2010.54533207

Liu, D., Liao, H., \& Loi, R. (2012). The Dark Side of Leadership: A Three-Level Investigation of the Cascading Effect of Abusive Supervision on Employee Creativity. Academy of Management Journal, 55, 1187-1212. https://doi.org/10.5465/amj.2010.0400

Ma, Y., \& Cheng, W. (2013). Linking Ethical Leadership to Employee Creativity: Knowledge Sharing and Self-Efficacy as Mediators. Social Behavior and Personality, 41, 14091419. https://doi.org/10.2224/sbp.2013.41.9.1409

McAllister, D. J., \& Bigley, G. A. (2002). Work Context and the Definition of Self: How Organizational Care Influences Organization-Based Self-Esteem. Academy of Management Journal, 45, 894-904. https://doi.org/10.2307/3069320

McCormick, M. J. (2001). Self-Efficacy and Leadership Effectiveness: Applying Social Cognitive Theory to Leadership. Journal of Leadership \& Organizational Studies, 8, 22-33. https://doi.org/10.1177/107179190100800102

Morris, M. W., \& Leung, K. (2000). Justice for All? Progress in Research on Cultural Variation in the Psychology of Distributive and Procedural Justice. Applied Psychology: An International Review, 49, 100-132.

Namie, G., \& Namie, R. (2000). The Bully at Work. Naperville, IL: Sourcebooks.

Preacher, K. J., \& Hayes, A. F. (2008). Asymptotic and Resampling Strategies for Assessing and Comparing Indirect Effects in Multiple Mediator Models. Behavior Research Methods, 40, 879-891. https://doi.org/10.3758/BRM.40.3.879

Rafferty, A. E., \& Restubog, S. L. D. (2011). The Influence of Abusive Supervisors on Followers' Organizational Citizenship Behaviors: The Hidden Costs of Abusive Supervision. British Journal of Management, 22, 270-285.

https://doi.org/10.1111/j.1467-8551.2010.00732.x

Restubog, S. L. D., Scott, K. D., \& Zagenczyk, T. J. (2011). When Distress Hits Home: The 
Effects of Contextual Factors and Psychological Distress in Predicting Employee Responses to Abusive Supervision. Journal of Applied Psychology, 96, 713-729. https://doi.org/10.1037/a0021593

Schat, A. C. H., Frone, M. R., \& Kelloway, E. K. (2006). Prevalence of Workplace Aggression in the U.S. Workforce: Findings from a National Study. In E. K. Kelloway, J. Barling, \& J. J. Hurrell (Eds.), Handbook of Workplace Violence (pp. 47-89). Thousand Oaks, CA: Sage. https://doi.org/10.4135/9781412976947.n4

Shalley, C. E., \& Gilson, L. L. (2004). What Leaders Need to Know: A Review of Social and Contextual Factors That Can Foster or Hinder Creativity. The Leadership Quarterly, 15, 33-53.

Shalley, C. E., Gilson, L. L., \& Blum, T. C. (2009). Interactive Effects of Growth Need Strength, Work Context, and Job Complexity on Self-Reported Creative Performance. Academy of Management Journal, 52, 489-505.

https://doi.org/10.5465/AMJ.2009.41330806

Shin, S. J., \& Zhou, J. (2003). Transformational Leadership, Conservation, and Creativity: Evidence from Korea. Academy of Management Journal, 46, 703-714. https://doi.org/10.2307/30040662

Sutton, R. I. (2007). The No Asshole Rule: Building a Civilized Workplace and Surviving One That Isn't. New York: Warner Business Books.

Tepper, B. J. (2000). Consequences of Abusive Supervision. Academy of Management Journal, 43, 178-190. https://doi.org/10.2307/1556375

Tepper, B. J. (2007). Abusive Supervision in Work Organizations: Review, Synthesis, and Research Agenda. Journal of Management, 33, 261-289.

https://doi.org/10.1177/0149206307300812

Tepper, B. J., Carr, J. C., Breaux, D. M., Geider, S., Hu, C., \& Hua, W. (2009). Abusive Supervision, Intentions to Quit, and Employees' Workplace Deviance: A Power/Dependence Analysis. Organizational Behavior and Human Decision Processes, 109, 156167.

Tepper, B. J., Duffy, M. K., Henle, C. A., \& Lambert, L. S. (2006). Procedural Injustice, Victim Precipitation, and Abusive Supervision. Personnel Psychology, 59, 101-123. https://doi.org/10.1111/j.1744-6570.2006.00725.x

Tepper, B. J., Duffy, M. K., Hoobler, J. M., \& Ensley, M. D. (2004). Moderators of the Relationship between Coworkers' Organizational Citizenship Behavior and Fellow Employees' Attitudes. Journal of Applied Psychology, 89, 455-465. https://doi.org/10.1037/0021-9010.89.3.455

Thau, S., Bennett, R. J., Mitchell, M. S., \& Marrs, M. B. (2009). How Management Style Moderates the Relationship between Abusive Supervision and Workplace Deviance: An Uncertainly Management Theory. Organizational Behaviour and Human Decision Processes, 108, 79-92.

Tierney, P., \& Farmer, S. M. (2002). Creative Self-Efficacy: Its Potential Antecedents and Relationship to Creative Performance. Academy of Management Journal, 45, 1137 1148. https://doi.org/10.2307/3069429

Tu, Y., \& Lu, X. (2012). How Ethical Leadership Influence Employees' Innovative Work Behavior: A Perspective of Intrinsic Motivation. Journal of Business Ethics, 116, 441455.

Tyler, T. R., Lind, E. A., \& Huo, Y. J. (2000). Cultural Values and Authority Relations: The Psychology of Conflict Resolution across Cultures. Psychology, Public Policy, and Law, 6, 1138-1163. https://doi.org/10.1037/1076-8971.6.4.1138

Wu, J. B., Tsui, A. S., \& Kinicki, A. J. (2010). Consequences of Differentiated Leadership 
in Groups. Academy of Management Journal, 53, 90-106.

https://doi.org/10.5465/AMJ.2010.48037079

Xu, E., Huang, X., Lam, C. K., \& Miao, Q. (2012). Abusive Supervision and Work Behaviors: The Mediating Role of LMX. Journal of Organizational Behavior, 33, 531-543. https://doi.org/10.1002/job.768

Yamada, D. C. (2004). Crafting a Legislative Response to Workplace Bullying. Employee Rights and Responsibilities Journal, 8, 475-521.

Zhang, A. Y., Tsui, A. S., \& Wang, D. X. (2011). Leadership Behaviors and Group Creativity in Chinese Organizations: The Role of Group Processes. The Leadership Quarterly, 22, 851-862.

Zhang, H., Kwan, H. K., Zhang, X., \& Wu, L. Z. (2014). High Core Self-Evaluators Maintain Creativity: A Motivational Model of Abusive Supervision. Journal of Management, 40, 1151-1174. https://doi.org/10.1177/0149206312460681

Zhou, J. (2003). When the Presence of Creative Coworkers Is Related to Creativity: Role of Supervisor Close Monitoring, Developmental Feedback, and Creative Personality. Journal of Applied Psychology, 88, 413-422. https://doi.org/10.1037/0021-9010.88.3.413

Zhou, J., \& George, J. M. (2003). Awakening Employee Creativity: The Role of Leader Emotional Intelligence. The Leadership Quarterly, 14, 545-568.

Zhou, J., \& J. George, M. (2001). When Job Dissatisfaction Leads to Creativity: Encouraging the Expression of Voice. Academy of Management Journal, 44, 682-696.

https://doi.org/10.2307/3069410

\section{Submit or recommend next manuscript to SCIRP and we will provide best service for you:}

Accepting pre-submission inquiries through Email, Facebook, LinkedIn, Twitter, etc. A wide selection of journals (inclusive of 9 subjects, more than 200 journals)

Providing 24-hour high-quality service

User-friendly online submission system

Fair and swift peer-review system

Efficient typesetting and proofreading procedure

Display of the result of downloads and visits, as well as the number of cited articles

Maximum dissemination of your research work

Submit your manuscript at: http://papersubmission.scirp.org/

Or contact ojl@scirp.org 